\title{
Chinese Tour Guides' Strategies in Intercultural Communication-Implications for Language Teaching and Tourism Education
}

\author{
Ying Huang \\ School of Foreign Languages \& Literature, Yunnan Normal University, Kunming, China \\ Email: nancyhuang1207@yahoo.com.cn
}

\begin{abstract}
This paper presents Chinese tour guides' strategies in intercultural communication. It is based on a research carried out in Yunnan Province of China to explore intercultural communication of professional English-speaking tour guides with their tourists from various cultural backgrounds. Findings indicates that faced with the prospect of conflict with tourists, or between tourists, guides will adopt varied strategies according to which roles, identities and relationships they choose to identify as most appropriate in the particular situation. Role, identity and relationship are important; context is important, and individual perceptions of appropriateness are also strong influences on the guides' responses. What influences tour guides' choice of strategies and leads to their perceptions is a complicated issue. It has to be understood and explained with due consideration of personal, cultural and contextual perspectives.
\end{abstract}

Index Terms - tour guides, strategies, intercultural communication, context

\section{General InTROduction}

In China, communication between tour guides and their international tourists has drawn attention of researchers in recent years for two reasons: Firstly, the number of international tourists coming to China has been increasing rapidly; Secondly, intercultural communication studies has been identified as an important research area. The importance of this has become obvious, particularly in China where tourism is booming and the number of tourists coming from other cultures has been increasing rapidly in the past 20 years. Aroused by the interest and demands to find out the answers on how tour guides are communicating with their international tourists to achieve their perceived effective and appropriate communication and what are the relevant factors in relevance to their strategies, a research was conducted focusing on professional tour guides in Yunnan province of P. R. China. Many interesting findings have emerged from the research, which have good implications for developing intercultural communicative competence and tour guide training in China.

Yunnan as the gateway to Southeast Asian countries has experienced rapid tourism development in the past 20 years or so. The increase of international tourists to the province adds to the demand for foreign language speaking tour guides. In international tourism context, tour guides are playing multiple roles when communicating with international tourists. Meanwhile their communication with tourists takes place in a complicated and multiple contexts characterized as professionalism, commercialization and Chineseness (Huang, 2008). This makes their work quite challenging and places them in front of choices from time to time.

\section{RESEARCH METHODOLOGY}

The methodology of grounded theory was used to the extent that new themes are allowed to emerge in the research process. Grounded theory is a qualitative approach that generates theory from data. It was developed by sociologists Glaser and Strauss (1967). This approach provides the structure often lacking in other qualitative approaches without sacrificing flexibility or rigour. One essential characteristic of this methodology is that the knowledge or theory emerges from the data collected (Lincoln \& Guba, 1985). It allows whatever is salient to the area being studied to emerge. It also stresses the importance of the researcher's role as an interpreter.

Data for this study was drawn by three means: semi-structured interview, participant observation and document analysis. Interviews are widely regarded as an appropriate means to acquire data in qualitative research (Denzin, 1989). Fontana \& Frey (2000) identify interviews as the most common and powerful ways that people try to understand their fellow human beings. Semi-structured interviews were conducted with 19 Chinese English-speaking tour guides and 5 tourism educators to find out their perceptions of the issue being explored.

Participant observation was also employed as a complementary approach for data collection. This method is regarded as one that is suitable for a study of people. The aim of this method is "to generate practical and theoretical truths about human life grounded in the realities of daily existence, and by this the researcher is able to experience or observe the meanings and interactions of people from the role of an insider" (Jorgensen, 1989: 14). It is used as a supplementary tool to compare what tour guides talked about with what happens in reality, and to cross validate interviews. Six tour 
guides were observed when they conducted their 131 international tourists from America, Australia, Britain, Sweden, Poland and Holland. The total length of observation is 13 days. Analysis of the findings has many implications for improving intercultural communicative competence, language teaching and tourism education.

\section{STRATEGIES TOUR GUIDES USED IN THEIR COMMUNICATION WITH INTERNATIONAL TOURISTS}

Findings of the research has indicated that tour guides' strategies to achieve their goals of effective and appropriate communication are based on context, tourist and perception of roles. The major ones are labeled as: adaptation to cultural differences; adopting appropriate skills; creating similarities; maintaining appropriate relationships and conflict resolution strategies.

\section{A. Adaptation to Cultural Differences}

Tour guides have to work with tourists from varied cultural backgrounds. The guides unanimously identified a common approach - adaptation to the differences between themselves and the tourists, and to differences among the tourists. From their perspective it was the tour guides rather than the tourists who adapted.

Several guides indicated that this adaptation was not based on knowledge of professional roles or intuition. To adapt successfully requires knowledge of cultural differences. This knowledge revolves around two aspects: adaptation to style and to interests. Adaptation to cultural styles is influenced to some extent by group size, but mainly by cultural differences and ways of communicating such as ways of talking, e.g. the appropriate use of words, and the style of communication. In accordance with the group and tourists, some tour guides emphasised the effectiveness of giving systematic introductions to tourists who are travelling long-distances. On these occasions, they usually organised her interpretation as a series of special topics. Their style is more like lecturing in a classroom. However they always made sure that their body language matched the requirements of tourists, and that tourists' needs were catered for.

The guides' comments suggest they are fully aware that understanding cultural differences is quite helpful for effective and appropriate communication. This understanding helps tour guides adapt to tourists' interests and needs when giving speeches or interpretations, and to other factors such as age and educational background. One guide used a Chinese idiom to describe its importance: "zhi bi zhi ji" (know both our adversaries and ourselves). By this he emphasised that tour guides should know both Chinese culture and tourist culture, and that only by this adaptation could the two sides understand each other and have in-depth communication.

With this perception, tour guides used strategies to discover tourists' interests and then to adapt to them as far as is practical. Some took into consideration what their coming tour groups would be interested in when they received the itinerary.

Nevertheless, the guiding strategy of adaptation does not mean abandoning the principles relating to the proper roles and identities of tour guides. Some strongly emphasised that adaptation to cultural difference does not mean to totally "give in" or "surrender with no principle". This is especially so for adaptation to tourists' interests.

Data from the research suggests that the younger tour guides saw adaptation as about practical strategies such as matching their styles of dress and skills, while the more experienced tour guides emphasised adaptation from a deeper level, which includes knowledge and attitude. This difference in styles of adaptability was reflected in the generational tension over what it means to be sensitive to differences among tourists, in an unexpected way. A senior tour guide, when commenting on the younger generation, stressed that in his time tour guides never sat down while delivering a speech on the coach. He mentioned how hard they worked at that time when the road conditions were bad. In the early years it took them about three hours travelling from Kunming to the Stone Forest, a journey which only takes 90 minutes at present. At that time, the road was very bumpy and zigzagging. Tour guides started delivering their speech soon after they got on the coach. Sometimes they stood for more than two hours, giving interpretations about what they saw along the road, introducing the culture of Yunnan, and organising activities to entertain the tourists. He complained that the younger tour guides would too often relax by sitting down with their backs to the tourists if they sensed that particular tour groups did not demand constant information through lectures lasting the duration of the coach ride.

\section{B. Developing a Wide Repertoire of Communication Skills}

Being aware that they have to adapt to cultural differences in order to have effective and appropriate communication with international tourists, both tour guides and tour educators argued that developing a wide array of appropriate and varied communication skills was essential. These skills include the areas of language, motivation, entertainment and engaging tourists, and dealing with embarrassing situations.

The guides are careful about language skills, including different vocabulary, tones and speed to communicate with varied tourists. Interviews and participant observations indicate that most tour guides had developed these skills to a high degree. One tour guide conducting an American group presented her good skills in communication. Her language was very effective in arousing interest and engaging tourists. For example, she said, "Yi people, after they get married, only use two colours for clothes, blue and black. ... If you touch their triangles and don't want to marry them, you offend them and have to labour for three years for the family. You don't want to marry them, do you?". Tourists burst into laugh.

There are also occasions when tour guides have to fabricate stories or words in order to achieve their goal, but at the 
same time cover their real purposes. This often happens when they are heading for tourist shops, which is mandatory for tour guides and tour companies. Sometimes shopping is included in the itinerary, so tour guides must take tourists there, for they have to sign a paper in the shop to prove they have visited. It is a sensitive issue because it is concerned with taking commissions. Realizing that most tourists are sensitive to this arrangement, and that some of them might have negative attitudes towards it, some tour guides use techniques in their communication to make tourists happy and to cover this up.

\section{Creating Similarities}

One common factor in tour guides' strategies is their awareness of the need to create perceived similarities between people from different cultures in order to cross cultural boundaries and to engage tourists in communication.

To contrast and compare is also a suggested effective strategy to help tourists understand Chinese culture. To some extent, it is a way to create similarities between cultures, making it easier for mutual understanding. For example, one tour guide realised it was hard to explain and make tourists understand Buddhism which is widely practised in China, so he compared the doctrines and practice of Buddhism with Christianity and other religions. This made things easier for both tourists and tour guides. On this point of comparison and contrast, guides again raised the importance of knowledge of cultural differences, which helps to create similarities and to cross boundaries between cultures.

Some tour guides use anecdotes and legendary stories in their cultural interpretation. Yunnan is a province with 26 ethnic groups, each of which has its legendary stories concerned with customs and culture. Many touching love stories are concerned with local residential construction, festivals and customs. Some tour guides usually drew comparisons between Chinese and western love stories such as Romeo and Juliet, making it easier for tourists to understand.

\section{Maintaining Appropriate Relationship}

The informants in this research have indicated their emphatic attitudes towards relationships with tourists. In particular, they empahsised different relationship with domestic and international tourists.

One tour guides said that to set up a good relationship with the person who had the role of leader was very important with both international and domestic tourists. However, this strategy was more critical with Chinese tourists. Once a good relationship was set up with the head of the group, it was easier to deal with the whole group; hence one of her effective strategies was to identify the key person in a group. She is smart to rely on that "powerful person" to exercise her own power on the group. She said that strategy was not quite as effective with international tourists because their relationships were less hierarchical, even though they might come from the same company. With domestic tourists she was concerned not only for her relationship with them, but also for the relationships among tourists themselves, and their subtle psychological differences.

To maintain good relationships through such strategies does not always work, because other people's needs and power sometimes intrude into the equation. Some tour guides, especially the younger ones, talked about their problematic relationship with coach drivers, who they were forced to be careful of not offending. They sometimes have to give in to the drivers at the expense of good communication with the tourists.

Tour guides understand that maintaining appropriate relationships involves skills. Some use much singing and stories to engage tourists. One guide said that she understood that "ren qing wei" (human feeling) between tourists and tour guides helps to initiate effective communication.

\section{E. Conflict Resolution}

As presented in the previous section, tour guides contend there are not many conflicts with their tourists. This is because it is mandatory that they minimise conflicts and avoid them before they appear. Nevertheless, there are occasions when conflicts do occur and manipulation of them demands a negotiation. When the conflict occurs, two strategies are often used: to find safe topics and avoid touchy ones. However, once confronted with conflicts, there are different strategies — to give in or to confront.

To sum up, tour guides' perceptions indicates that effective and appropriate communication is context-based. This context is relevant to the profession, the social context and personal perception of roles, identities and relationships. In addition it concerns expectations of the results of communication. To a large extent, these tour guides are trying to achieve their expectations through effectiveness and appropriateness. This involves varied choices. These choices relate to negotiating cultural differences, perceiving professional appropriateness, targeting communication, managing identity conflicts and maintaining relationships.

Consciously or subconsciously, tour guides are trying to build up a third culture in which both sides could share some temporary similarities with which they are to communicate effectively and appropriately within a certain period of time. To build up a third culture not only includes creating common interests, emphasising similarities, and sharing professional rituals. It also requires politeness, face and respect. These components can interact at several levels. First, this third culture should be acceptable to both sides for at least the duration of the tour; both sides agree on content and itinerary and shared interests; they cooperate to achieve their goals of communication; both sides accept the commercial base, including rules of good service and payment. Second, this third culture should be one in which both sides try to appreciate and understand the others, both from the perspective of professional tourists and guides, and also through personal qualities and politeness. 


\section{IMPLICATIONS FOR TOURISM EDUCATION AND TRAINING}

The findings of this research have generated some implications for both tour guide training and tourism education, and in improving intercultural communicative competence. In particular, they make one ponder on questions such as: Can tour guides be trained in the knowledge and behaviour required to meet tourists' demands? What should be included in the training and what approaches are effective in training? And this research has implications for training and education in Yunnan and in China. This is summarised in the following seven points:

(1). Mindfulness, context-based communication and third culture creation imply that we should go beyond skill-based and competence-based training towards an education that develops abilities in perception and attribution. The final goal is a mindful communication. This is particularly necessary for tour guides working with international tourists who are varied in values, customs, behaviours and communication styles. For tour guides to have good communication skills, they should first of all understand tourists as human beings, at least the general or universal characteristics of human beings. This includes tour guides understanding themselves as human beings.

Equally important is developing a proper attitude towards this profession, which is also a process that takes time and energy. It is hard to achieve through short-term training. If tour guides could see their intercultural communication as an interactive process in which they could learn real-life communicative competence by offering good service and sincerity, they would better enjoy the work.

(2). Training should involve a change from content-based or information-focused teaching to one that not only provides students with information, but also a way of thinking, and a way of solving problems. Effective and appropriate communication requires communicators to acquire knowledge of different cultures. Tour guides understand this. However, on many occasions, cultural teaching is a teaching of stereotypes with an absence of context and an ignorance of individual differences.

The acquisition of cultural general and cultural specific knowledge, however, not only includes foreign but also Chinese culture. An analysis of tour guides themselves as human beings, an understanding of their own culture and the behaviour brought about by this culture will benefit tour guides in many ways. Tour guides would have a chance to think about themselves, who they are and what they are actually expecting from this profession. It would also be a chance for tour guides to bravely face their own shortcomings, especially those that they might perceive in their own compatriots. They would feel shame at the some of the behaviours shown by domestic tourists, especially when they get the chance to compare and contrast with international tourists, who in some aspects, behave in ways they perceive to be polite, respective and cooperative. If tour guides are mindful of these differences, they are more likely to have reasonable attributions when problems and conflicts occur. They might be more motivated to find ways to cooperate and adapt to domestic tourists.

These suggestions, however, do not mean that the essential competencies should be ignored. On the contrary, this research indicates a need for a strong emphasis on these basic competencies and skills. It suggests that language is essential in contributing to a good trip. For tour guides, language should also include training for tourism and hospitality purposes, because how to make guests feel welcome and well-attended is an art. They should learn how to speak clearly to guests, how to engage tourists with appropriate language skills, and how to use language as a professional skill for self-presentation and impression management, although success in communication goes beyond skill-based competence.

(3). There should be some consideration from educators and trainers about their ways and methods, or methodology in training and education. Approaches such as contextualising the problem and applying theory to practice should be used. This research has indicated a gap between practice and teaching or, in another words, a divorce of theory and practice. Many tour guides pointed out that what they had learned at school was not applicable in reality. This is a common problem existing in the Chinese education system. Schools offer courses and design their curricula according to educators' wishes instead of employers' demands and what learners need to succeed after graduation (Xiao, 2000). Educators emphasise content and language competence. While this is definitely essential, there are also other perspectives that they should include such as contexts for conducting the tour. Unfortunately, the basic universal human needs and expectations are usually neglected. But effective communication ideally involves satisfying the expectations of both sides (Ting-Toomey, 1999). More cooperation and communication between educational providers and tourism industries should be developed to make sure that they are moving in a reasonable direction.

(4). Training strategies appropriate for Chinese culture and Chinese students for communicating with international tourists should be developed. In order to be a top class, competent professional tour guide, one needs to work from a solid basis of knowledge of himself or herself. It is important to know oneself as Chinese. This is not a similar notion to western identity, but to know oneself as Chinese. They need that to develop a fully professional code of ethics and a notion of treating people mindfully. Then they are able to treat Chinese tourists mindfully, not just international tourists.

(5). Professional ethics should be enhanced. The respondents have pointed out some misunderstandings in social attitudes towards the tour guiding profession. However, these people also indicated that ethics was a concern for the profession. Some tour guides used inappropriate, even illegal, approaches to obtain financial benefit. The older generation blames the younger tour guides for targeting financial reward with no consideration of identity and professional ethics. They attribute the decay to the social environment and managerial system. None of the younger tour guides talked about their own professional ethics except that some blamed their peers for bad behaviour. They isolated 
some tour guides as "hai qun zhi ma" (black sheep), who damaged their professional reputations. The implication is that whoever is to blame, professional ethics deserves more attention, although it is the most difficult issue to be dealt with. It is not a problem which can be solved through short training or lecturing: it is an issue involving education, understanding and social support.

(6). This research also implies challenges for tourism educators. Being involved in an industry which demands competencies, attitudes and knowledge, tourism educators have to face challenges from a rapidly developing and changing society. They need to envision the change, be engaged in the changing process, update their knowledge, and be open to the ever-changing world. On the one hand they cannot impose their ideas on their students. The paradox appears when they have to convince their students of the importance of the profession. They cannot convince their students or understand their worldview until they themselves develop this insight, and be ready to accept and respect the diversity. Globalisation has forced China to change some forms of teaching, both academically and methodologically. For example, the training should not only be the traditional content-oriented, but also process-oriented, such as the process of communication, how to be mindful communicators, how to ask questions and how to reflect.

\section{CONCLUSION}

In sum, the research indicates that in-service professional training is very important, but should be treated as a long-term strategic plan for cultivating personnel for the tourism industry and the whole society. There is the distinction between training and education. Hence the question whether we should teach tour guiding as an educative process or just as training for communicative skills and professional competence.

The findings in respects of strategies adopted have many implications for both language teaching and tourism education. It has helped to draw a conclusion that to face the development of tourism industry and globalization, we should go beyond training to education. This is because for service industries, competence and skills are necessary, in which case both long-term and short-term training are essential. However, competence-based and skill-based training are not enough for good communication with people of individual and cultural difference. Proposing education as the means to meet the demands of the market and society does not mean advocating professional training in order to satisfy employers' or trainees' short-term demands. Rather, education should be advocated as a process for cultivating good tour guides in the long term. Students should not only understand the nature of this profession, but also understand tourists as human beings. It is more important that teachers teach students the rationale of "why" some principles should be followed and why some techniques should be used. Then students could apply them in their practice.

\section{ACKNOWLEDGEMENT}

This is supported by Yunnan Provincial Department of Education Research Fund (Project No. 08Y21045).

\section{REFERENCES}

[1] Huang, Y. (2008). A Study of intercultural communication of professional tour guides in China. Yunnan People's Publishing House.

[2] Glaser, B., \& Strauss, A. (1967). The Discovery of Grounded Theory: Strategies for qualitative research. Chicago: Aldine-Atherston.

[3] Lincoln, Y. S., \& Guba, E. G. (1985). Naturalistic Inquiry. Newbury Park, London, New Delhi: SAGE Publications.

[4] Denzin, N. K. (1989). The Research Act: A theoretical introduction to sociological methods ( $3^{\text {rd }}$ ed.). Englewood Cliffs, NJ: Prentice Hall.

[5] Fontana, A., \& Frey, J. H. (2000). The Interview: From structured questions to negotiated text. In N. K. Denzin \& Y. S. Lincoln (Eds.), Handbook of Qualitative Research ( $2^{\text {nd }}$ ed.). Thousand Oaks, London, New Delhi: SAGE Publications, pp645-672.

[6] Jorgensen, D. L. (1989). Participant Observation: A methodology for human studies. Newbury Park, CA: SAGE, p14.

[7] Xiao, H. (2000). China's tourism education into the 21st century. Annals of Tourism Research, 27(4), 1052-1055.

[8] Ting-Toomey, S. (1999). Communication across Cultures. New York, London: The Guilford Press.

Ying Huang was born in Yunnan, China in 1968. She received her M.A. degree in 1997 in Applied Linguistics and her Ph. D degree in 2005 in Intercultural Communication, both from La Trobe University in Australia.

She is currently an associate professor in School of Foreign Languages \& Literature of Yunnan Normal University, Kunming, China. Her research interest is intercultural communication and EFL. 